\title{
LEGAL TERMINOLOGY AND LESSER USED LANGUAGES: THE CASE OF MÒCHENO
}

\section{ELENA CHIOCCHETTI}

Elena.Chiocchetti@eurac.edu

NATASCIA RALLI

Natascia.Ralli@eurac.edu

European Academy of Bolzano, Bolzano, Italy

\author{
Bos as gaben ist, kimp nea'mer, \\ $s$ sèll as ist, mechet ònderst sai', \\ kenn ber bèckschln s sèll as sai' bart? ${ }^{1}$ \\ (Bersntoler Kulturinstitut 2010)
}

\begin{abstract}
The article aims at outlining the specific problems connected with the elaboration of legal and administrative terminology in a lesser used language and illustrating the methods and tools proposed considering the knowledge and competences to be conveyed.

Since 2003 the Institute for Specialised Communication and Multilingualism of the European Academy of Bolzano (EURAC) offers education courses in legal terminology work, coupled with introductions in related/complementary disciplines, e.g. documentation, specialised translation and technical writing. Next to professional trainings, the Institute held also ad-hoc courses, such as a two-day course organised in 2008 for the Mòcheni, a Germanic minority living in the Italian Province of Trento. Since the passing of provincial law no. 6/2008, which foresees specific measures for the protection and promotion of local language minorities, the Mòcheno-speaking community has the right to use their language in all situations of social, economic and administrative life in both oral and written communications. Notwithstanding the recent compilation of a standard grammar, the Mòcheno language is not yet developed for the use in technical and specialised contexts. Indeed, the most urgent needs seem to exist in the translation of administrative terminology.
\end{abstract}

Key words: legal terminology, terminology training, lesser used languages, Mòcheno, language planning

\footnotetext{
${ }^{1}$ What has been will not come back, what is should be different, can we change what is going to be?
} 


\section{Introduction and background ${ }^{2}$}

Chi dice comunicazione specialistica, dice terminologia, ovvero 1) il vocabolario proprio a un settore; 2) l'attività che rileva, crea e dà forma al vocabolario di un settore (denominata anche terminografia); 3) la disciplina che definisce i fondamenti teorici della terminologia. (Pulitano 2006)

Terminology is a discipline that combines elements of applied linguistics (in particular, lexicology, translation studies, language teaching and pragmatics) with techniques of information science. Defined as the "study of concepts and their representations in a special language" (ISO/TC37/SC1 N165 E: 6), terminology represents the central component of specialised communication and knowledge transfer between individuals and/or organisations. At the same time, it is also the main means of overcoming language barriers in order to ensure communication among different countries and, therefore, to enable mutual understanding. Hence, terminology is everywhere where there is the need for writing, translating, interpreting, reviewing or reading a text. Consequently, it plays a key role in knowledge management: terminology supports communication in all its forms, helps avoid misunderstandings due to intralinguistic and interlinguistic ambiguities and reduces the time required to find the "right" word (see Pulitano 2006). The importance of its correct application in order to guarantee the certainty of communication and the correctness of interpretation is evident. The use of incorrect or inconsistent terminology can reduce the quality of a product, cause misunderstandings and hence lead to additional costs (e.g., misdelivery, delay in delivery) or even to legal disputes (e.g., producer liability).

In order to avoid these problems, terminology requires precision in the study of the subject field, a good feeling for problems in intercultural communication and awareness of the possible consequences which an incorrect term or-from the point of view of translation - an incorrect equivalent can cause. Since 2003 the Institute for Specialised Communication and Multilingualism of the European Academy of Bolzano (EURAC) has offered post-graduate education courses in terminology work, in particular in legal terminology work, coupled with courses in related and complementary disciplines: documentation, specialised translation and technical writing, to name but a few. Dealing with communication requires intertwined abilities, such as, for example, the ability to write clearly and competently in one's native language using different linguistic registers and a large and flexible vocabulary; the inclination to investigate meanings in order to create terminological entries or understand the text to be translated; and the competence to efficiently evaluate documentation. These abilities must be accompanied by a

\footnotetext{
${ }^{2}$ The present article was drafted by the two authors in close collaboration, from the initial research (design, discussion) to the final written version; nevertheless, responsibility for the sections shall be attributed as follows: Elena Chiocchetti is responsible for the sections 4 to 6, Natascia Ralli for the sections 1 to 3 .

3 Those who talk about "specialised communication" talk about terminology, i.e., 1) the vocabulary of a specific subject field; 2) the activity which collects and describes the terms of a specific subject field (also called "terminography"); 3) the discipline defining the theoretical aspects of terminology.
} 
thorough knowledge of the specialised subject fields in question, curiosity and good general knowledge as well as the complete mastery of working methods and tools.

Over the past few years in addition to education courses (training for work and lifelong learning) addressed to a wide audience (e.g., legal practitioners, translators, students, graduates in translation studies), the Institute also has held ad hoc courses, such as a two-day course organised in 2008 for the Mòcheni, a Germanic minority living in the Italian Province of Trento.

This article aims at outlining the specific problems connected with the elaboration of legal and administrative terminology in a lesser used language and illustrating the methods and tools proposed, based on the knowledge and competences to be conveyed. In the first section, the training in legal terminology is introduced by briefly describing the specific problems of this field, the requirements needed, the related disciplines that contribute to terminology and the training components. In the second section, the Mòcheno language community and its characteristics are described and the problems and challenges related to terminology work in a lesser used language are outlined. The final section illustrates the differences between "standard courses" in multilingual legal terminology and "ad hoc courses" for languages that are used by a small number of citizens.

\section{Training in legal terminology work}

Language and law are intertwined: law expresses itself through language and in particular through its own legal jargon, which is characterised by specific mental categories and concepts and may differ considerably between distinct legal systems. So, translating a legal text, or even just finding an equivalent term in another legal system, does not only consist in the simple search for a linguistic label and, therefore, in the shift from one language to another, but also from one legal system to another (Kerby 1982 in de Groot 1999: 18). Consequently, the translation of legal texts does not only require linguistic and cultural knowledge about the source language, but also knowledge about the legal context (where the terms of the source language acquire a specific meaning) and the legal system in which the target text will be used.

From the perspective of translation, aspects of non-equivalence, polysemy/homonymy, neologisms and terms which are difficult to translate because of their geographical, historical and cultural connotation, cannot be overlooked. So, for example, earthquake terminology is well described in the Italian city-planning law, unlike in the German one. The reason probably lies in the fact that Germany is not a highly seismic zone (Ralli 2006: 120).

Working with language and law does not always involve the need to deal with different national languages and distinct legal systems. Language varieties and linguistic registers, which must be considered, coexist even in the same language. So, for example, traffic law talks about "intersezione a raso" or "intersezione a livello", but in everyday language the most current term is "incrocio" (crossroads). In family law the terms "vincolo matrimoniale", "vincolo coniugale" and "vincolo di coniugio" (marriage bond) are fully interchangeable (Ralli 2010). 
Language, law and technology evolve over time according to the evolution of society: as far as legislation is concerned, reforms are introduced quite frequently. Also the development and improvement of methods and tools require a continuous upgrading of skills in order to be maintain competitiveness on the market. Being aware of the existence of serious and peculiar problems related to the translation of legal terms as well as knowing a foreign legal language, are fundamental prerequisites for the success of communication processes.

As a consequence, terminology plays an important role in communication and represents the basis on which to build on. Legal texts need to be clear, correct and effective, both from the legal point view and from the communicative one (Fioritto 2007: 45). In order to do that, the following requirements are necessary (see also RaDT 2004):

- well-developed feel for the language and a high degree of linguistic creativity

- appropriate knowledge about the problems related to specific subject fields, taking into account the intercultural dynamics

- interdisciplinary thinking and comparative working methods

- $\quad$ systematic working methodology

- awareness of the importance of terminology in the translation process and, more generally, in editing

- awareness of the existing differences between legal systems, even when they use the same language

- awareness of the possible consequences of an incorrect translation;

- familiarity with legal language

- knowledge of the principles and methods of legal translation

- ability to apply principles of terminology theory and practice

- ability to identify the translation problems related to text production in the target language, including the level of terminology, as well as to recognise the extent of such problems and to work out solutions

- ability to apply appropriate micro-strategies for the production of a legal text in the target language

- ability to adapt the legal text of the source language to the new communicative situation

- mastery of traditional and electronic search and documentation tools used for the acquisition of information and the creation of glossaries and databases

In light of all of that, interdisciplinary aspects have to be considered in teaching legal terminology. From this point of view, a number of other topics and/or complementary disciplines should be treated. An outline of the main subjects to be taught follows.

- Introduction to the nature of legal language: it helps professionals in translation and terminology to become familiar with the language and the peculiarities (e.g., rules, conventions) of the law. Terminology should be discussed here with a focus on methods for identifying, describing and storing the concepts and related terms.

- Textual analysis: to evaluate text quality (e.g., intelligibility, correctness), in order to identify terms for a terminology collection and recognise potential translation problems related to text production in the target language at several 
levels (e.g., terminology, style). Recognising such problems helps finding strategies for solving them.

- Documentation: it provides the methods and tools needed to search for information so as to acquire familiarity with the language and the field of investigation. It also includes methods and strategies to evaluate the quality of information on the web, as well as other information resources, such as manuals, parallel texts, dictionaries, etc. on the basis of the parameters of authority, authenticity, reliability, objectivity, timeliness, relevance and efficiency.

- Micro-comparison: a type of research in comparative law which investigates concepts or aspects of two or more legal systems (Chiocchetti et al. 2009: 3) with the aim of acquiring more knowledge and identifying similarities and differences between legal systems (Pizzorusso 1995: 138, Chiocchetti et al. 2009: 3). From a terminological point of view, micro-comparison provides the basis for addressing translation gaps, terminological incongruities and equivalence between legal systems, both from the conceptual perspective as well as from the perspective of effectiveness and function.

Technologies (e.g. software, Internet) play an important role in terminology, too. The overlapping areas between computer science and translation or computer science and terminology become more and more frequent and decisive for anyone working in translation and terminology. Dedicated systems (e.g., terminology management systems, CAT-tools) and integrated programmes (e.g., databases, word processors) help to increase productivity and optimise the working process in terms of time and money.

\section{Important training factors}

Many different factors have to be taken into account in education courses. First, the aim of the course: Is it a short practice-oriented introductory course? Is it a refresher course? Is it a course for a specific audience? The aim determines the duration of the course, the contents to be treated and the target group to be involved. For example, a course for professional translators should be practice-oriented and designed to take advantage of specific tools for practical terminology work and translation (e.g., translation memories, terminology management systems). In this case, an overview of dedicated software products available on the market is advisable in order to help participants in the choice of the most appropriate tool for their work.

Secondly, the educational background: knowing if the attendees have a background in languages or law is necessary for the preparation of teaching material and the elaboration of subjects, namely for understanding which subjects can be briefly treated and which ones need to be discussed in depth. Related to that, a target group of students, translators or employees will require specific teaching methods and lead to different course durations. So, for example, a course for employees would focus only on the most relevant information and practical contents related to the specific activities of the target group. The main emphasis should be put on the problems they encounter in their daily terminology and translation practice with the aim of making them familiar with the methods needed for elaborating their own solutions. 
Even the technological competencies of the attendees can influence teaching methodologies. Ideally, they should all have the same level of experience with the technologies being taught.

Finally, it is necessary to know the needs, motivations and expectations of course participants. This kind of information can be gathered, for example, during an entrance examination. Some want to attend the course in order to fill specific gaps in their educational background (e.g., aspects of theory, knowledge gaps related to the faculty attended, etc.), to refresh their qualifications, acquire credits to transfer into a master of translation studies or even to become familiar with the use of gender-neutral language.

In post-graduate education courses the attendees often have a heterogeneous background. Usually, most of them have a background in (ordered by frequency): translation studies, language mediation and intercultural communication, foreign languages and literatures, and (rarely) in law. In other cases, attendees have different levels of background knowledge due to their age and work experience. Therefore, it is fundamental to create a common knowledge basis.

In the case of ad hoc courses, such as the course for the Mòcheno language community (see sections 4 and 5), other aspects also have to be considered. Such courses are often promoted by institutions in response to some specific need. Therefore, they have to be accurately designed with the focus on the problems the target group will (or could) encounter in their daily practice and on the strategies to be applied to reach a solution. This type of audience usually has different educational backgrounds and, sometimes, even no background in translation or languages studies at all, but just a practical background in "translation" (e.g., employees of the public administration with the task of translating circulars, contracts, etc., without any prior knowledge of translation theory). Usually this type of course is very short, practice-oriented and includes only the most relevant and fundamental information so as to give the participants a general overview of standard methodologies and available tools.

\section{The Mòcheno language community}

Mòcheno is a Germanic language spoken by about 1000 inhabitants of three municipalities located in the upper valley of the Fersina river (Abbruzzese 2005: 11), in the northern Italian province of Trento. More than half of the Mòcheno speaking population have left their places of origin and reside elsewhere. Altogether, during the last general census in 2001, about 2200 people declared themselves speakers of Mòcheno (Bersntoler Kulturinstitut 2010). The origin of this small Germanic language island amidst speakers of Italian dates back to the $13^{\text {th }}$ century when the first settlers, mainly from Bavaria but also from other German-speaking areas, came to cultivate the then uninhabited valley. A further wave of immigration followed a couple of centuries later, when more settlers from central Europe came to work in the copper, iron and silver mines (Istituto culturale mòcheno-cimbro 2010).

The relative isolation of the three municipalities of the valley, Fierozzo/Vlarotz, Frassilongo/Garait, Palù del Fersina/Palae en Bersntol, caused the development of slightly different language variants. In 2003 a standard grammar was published and 
attempts at creating a unified orthography and standard Mòcheno were started (Rowley 2003: 23).

An example of the language can be given with the version of the Christian Lord's prayer in Mòcheno:

\author{
Voter inger en himbl, \\ gahailegt kimmp der dai' $N{ }^{\prime}$ 'm, \\ der dai'raich schellt kemmen, \\ der dai'billn schellt tschechen, \\ en himbl abia as de eart. \\ $S$ proat van ollto gib ins hait. \\ Ont vargib ins de inger schuld, \\ Abia a biar vargem sa en de ingern schuldeger. \\ Tua'ins nèt varviarn, \\ over moch ins vrai van tschlècht. \\ (Prezzi 2004: 294)
}

Only in the last decade has the Mòcheno language been properly protected by state and regional laws. At the national level the community was granted extended rights in 1999 with law n. 482/1999, which lists twelve so-called "historic" language minorities in Italy that are to be safeguarded in their respective local territories. This official recognition was an important step for preserving Italy's historic multilingualism in general and the Mòcheno language and culture in our specific case.

Linguists recognise different factors for language preservation; these can be both internal and external to the community. The most important among the internal factors is indeed the degree of institutionalisation of the lesser used language. Conferring a language an official status entails its use in the public administration and official documents (cf. Eichinger et al. 2008: 12). This is an essential step, since

\title{
[...] le minoranze linguistiche oggi non possono più pensare di sopravvivere semplicemente con il tramandarsi la parlata nell'ambito familiare, come è avvenuto nelle generazioni passate. Sicuramente anche questo aspetto ha una sua importanza, ma non è più sufficiente. È necessario che la lingua minoritaria venga utilizzata a tutti i livelli, sia in famiglia come nell'amministrazione pubblica [... $]^{4}$ (Gino Fontana, responsible for relations with language minorities of the regional government, in Rowley 2003: 15).
}

The constant contact with the country of origin of the settlers is a further quite decisive factor for language preservation, as it keeps the channel to the centres of language innovation open, thus hampering a separate development or the freezing in time of the language variant spoken by isolated communities. This contact may consist of the arrival of new settlers or, for example, of the habit of sending students back to the mother country for higher studies (Eichinger et al. 2008: 12-13). The Mòcheno community has seen the last wave of immigration in the $16^{\text {th }}$ century; the exchange with the nearest

\footnotetext{
${ }^{4}$ Today language minorities can no longer survive only with passing down their language in the family, as was the case with past generations. This type of language transmission is indeed important, but not sufficient any more. The minority language must be used at all levels, i.e. both in the family and in the public administration.
} 
German speaking areas was partly kept up thanks to the kromeri, pedlars who travelled to sell goods in the nearby Tyrol, but this did not avoid the preservation of antique and unique language characteristics in Mòcheno.

Finally, another internal factor for language preservation is religious. For centuries the language communities that did not share the same confession with the surrounding population were more likely to live in isolation, avoiding contacts and mixed marriages (and hence potential assimilation), than others (cf. Eichinger et al. 2008: 13). This factor is not extremely relevant for the Mòcheno community, who mostly profess the Roman Catholic faith as do the neighbouring people.

As regards the external factors, the presence of a Dachsprache, a standardised and common means of communication used by the speakers of different dialects, especially as a written means, can be crucial. The attempts at standardising and unifying the different variants of Mòcheno through the grammar published in 2003 have only partly succeeded, but this will probably change in the next decades, as more people will have attended Mòcheno lessons at school or in evening classes. As Eichinger (et al. 2008: 14) points out,

[d]ie Schule spielt heute eine ungleich höhere Rolle für den Spracherhalt als vor 150 Jahren. Während etwa um 1850 erst zehn Prozent der schulpflichtigen Kinder eingeschult waren und die Analphabetismusrate entsprechend hoch war, ist heute das Beherrschen einer Sprache in Wort und Schrift eine grundsätzliche Voraussetzung. ${ }^{5}$

The kinship between the languages in contact (Eichinger et al. 2008: 13) is among the last external factors of language preservation we wish to shortly discuss. The assimilation of an alloglot group is in fact less likely when the majority language is of a different language group or family, as is the case with the Germanic Mòcheno surrounded by Italian (a Romance language). Last but not least, the social and psychological attitude of speakers towards their language can play an important role (Eichinger et al. 2008: 13-14). In recent years the awareness of having a unique and original language and culture has risen in the Mòcheno community; many are now proud of being part of the minority, while a few decades ago it was still a cause of embarrassment or even shame.

The official recognition of Mòcheno as a historic minority language in Italy in 1999 and the subsequent regulations, which allowed its use in the public administration and documentation, contributed strongly to this rise of awareness and change in attitude towards the language, both within and outside of the community. The legal frame around this change in status is very varied, ranging from national to provincial laws, and is based on article 6 of the Italian Constitution stating that "[t]he Republic protects linguistic minorities by special laws". The first step was taken with the aforementioned law n. 482/1999, which lists the minorities to be safeguarded and sets a clear territorial principle, meaning that only the speakers of a minority language actually living in certain municipalities shall benefit from the new law. In those areas the teaching and use

\footnotetext{
${ }^{5}$ Today school plays a more important role for language preservation than 150 years ago. While in 1850 only $10 \%$ of children attended school and the rate of illiteracy was consequently high, knowing how to speak and write a language today is a basic prerequisite.
} 
of the minority language is allowed in nursery schools as well as in primary and secondary education, in municipal council meetings, when dealing with public administration officials and Justices of the Peace. Official documentation can be drafted bilingually, however the Italian wording remains the only legally binding version. Finally, specific funding is allocated for the protection and promotion of all historic Italian minority languages.

A second essential step followed at the provincial level when law n. 6/2008 was passed, requiring official documentation to be always bilingual in the areas populated by a language minority. The local law also establishes the right to education in the minority language and considers the knowledge of the language as a preference criterion for public employment. This entails that it will be easier in future to find public officials who are proficient in the Mòcheno language in the territory.

It is against this legal background that the community of the Fersina Valley realized the need for the development of legal and administrative specialised language and terminology in their native language, so as to be able to convey highly specialised concepts effectively in written and oral official communication. The problems the Mòcheno translators face are quite different from the standard challenges posed by legal translation and terminology. Such specific needs and background conditions will be outlined in the next section.

\section{Outline of specific problems and challenges}

Mòcheno is a typically oral language that has never been used before in modern and complex administrative contexts. As a consequence, it faces several "deficiencies" if compared with widely used and well-standardised languages that have an official status in one or more national states. From the point of view of orthography and lexis, writers must cope with people's strong attachment to their own village variant and phonology, which partly leads to differences in writing and word choice, despite the standardisation efforts undertaken with the common grammar published in 2003. For example, one of the municipalities in the valley can be found spelled Palae en Bersntol or Palai en Bersntol. At the moment it is still early to predict the effects of this slow diffusion of the standard orthography and grammar, but this will probably change as the standard language is taught more and more at school and in evening classes. This is a problem that cannot be addressed adequately during translation and terminology lessons but should be solved within the community of Mòcheno speakers and writers.

The almost complete lack of normative references and textual corpora deprives legal drafters and translators of any written linguistic authority to be consulted in order to find specialised terminology and cues or ideas for translation proposals. What any translator or terminologist working on largely spoken languages would notice immediately is the general shortage of language resources in Mòcheno on the one hand and on the other hand the great disparity between the minority language and the languages it is in closer contact with, first and foremost Italian and then German. Whereas the latter has online monolingual and bilingual dictionaries, searchable collections of legislation, large textual corpora, specialised terminology databases and many other-often even freely available - tools, no such resources have ever been worked on for Mòcheno. An 
essential type of information conveyed during the translation and terminology course was a good introduction to the existing monolingual resources of Italian and German as well as many bilingual tools, with a focus on free of charge web-based resources. This served the double purpose of teaching the trainees how to retrieve information in the source language, which leads to a better understanding of the text to be translated and hence less difficulties in transposing it into Mòcheno, but also of making them familiar with all the possible tools they could set up for their own language. The bilingual resources can be used as a source of inspiration and suggestions when neologisms and translation proposals have to be created.

With this respect, the tools and strategies developed in the neighbouring province of Bolzano have proven to be quite useful. Since the end of World War I, when the formerly Austrian territory called Südtirol was transferred to Italy, the province of Bolzano has a large German speaking minority. These citizens were granted extended rights and a substantial autonomy several decades ago. Having come to enjoy the right to use the German language (standard German in this case) many years before the Mòcheni, the South Tyroleans have faced and already partly solved many challenges now faced by the smaller minorities. Bilingual collections of local legislation, databases of legal and administrative terminology, dictionaries, monolingual corpora, etc. already exist. The province of Bolzano even set up a Terminology Commission in charge of standardising the German translation equivalents for the Italian legal and administrative terminology, thus for the first time creating a German language terminology which reflects the Italian legal concepts and order. It seems extremely useful for the Mòcheni to be introduced into the South Tyrolean standardisation process, for them to gain insight into how new legal terminology can be created when no existing term can be borrowed from the Austrian or German legal systems due to insufficient or nonexistent conceptual correspondence between the Italian legal concepts and the foreign systems. The tools and terms developed and created by their more numerous German speaking neighbours can serve the Mòcheno translators and drafters as a source of suggestions and inspiration when proposing new special language terms in their own language. In this context, during the training great attention and an adequate amount of time had to be devoted to the rules and strategies for term formation (compounding, derivation, paraphrasing etc.), in order to provide attendees with enough theoretical insights into the creation and dissemination of neologisms.

A further challenge to overcome is that, given the small number of speakers, it is quite unlikely to find expert legal drafters, translators and terminologists who are also proficient in the Mòcheno language. Most of them work without any specific training, simply because they are proficient in the minority language. As a consequence, a course in specialised translation and terminology work would have to start with very basic introductions into translation and terminology theories and techniques. To facilitate the trainees' approach to specialised translation and terminology work, extremely simple and straightforward subject fields were chosen: the theory and basic strategies for terminology work (definition writing, essential and sufficient characteristics of a concept, examples of use, etc.), were explained first monolingually, using the domain of jams and marmalades. Translation was illustrated on the basis of tourist texts describing the valley and its attractions. One of the most difficult messages to convey was that there 
is never just one correct translation and that the same message may be delivered in several ways and through different words.

Considering that the course was aimed at non-expert translators and terminologists it was deemed essential to provide them with an in-depth overview of the characteristics of Italian legal language and terminology, with the purpose of refining their abilities in detecting certain structures, differences in register, subtleties in the wording etc. in the original language. Once these are readily recognised they can be reproduced more easily in the target language, if this is possible and desired. Also, a good training in identifying translation problems allows the translator to decide more consciously which solutions can be viable or should be avoided.

From a more technical point of view, the Mòcheno community needed expert advice on the tools to be adopted or developed on the basis of their purpose, target audience and situations of use. The possible creation of a database of legal and administrative terminology called for background information on the selection and structuring of data categories in a term base as well as an overview of existing commercial and non commercial tools for terminology management.

\section{Conclusions and outlook}

All these aspects cause the activities related to translation and terminology to be very different when dealing with languages that are used by a small number of citizens and have very few financial and computational resources. Especially work on term formation and neology is extremely demanding and calls for specific training.

Concentrating on the aspects of terminology training, several adaptations of the "standard courses" in multilingual legal terminology work need to be carried out. Instead of teaching the basics of comparative legal terminology, the focus is laid on neology, since we are not comparing two fully-fledged legal systems; in fact, it is one and the same legal system that needs to be expressed in two languages, one of which lacks the specialised terminology that must still be developed. While standard terminology activities can often count on several tools developed for well-known languages and similar or equivalent tools can be found for both the target and source language, the terminologists working with Mòcheno can resort to useful tools only in the source language. Hence, the main difference in the two types of terminology work lies in the focus on term retrieval strategies in the first case and neology in the second.

These substantial differences confirm the need for specific terminology training to answer special needs, which focus on the strategies for countering the lack of existing tools and references. It seems desirable to develop tailor-made guidelines for terminology work on minority and lesser resourced languages in future to support the use and development of these languages and allow them to become fully fledged even from the point of view of specialised terminology. 


\section{References}

Abbruzzese, Salvatore et al. 2004. Minoranze in azione. L'esercizio quotidiano dell'identità. Trento: Provincia autonoma di Trento.

Bersntoler Kulturinstitut http://www.bersntol.it $/ \mathrm{cms}-01.00 /$ articolo.asp?IDcms $=88 \& \mathrm{~s}=98 \& \mathrm{l}=\mathrm{IT}$ (08.07.2010)

Chiocchetti, Elena, Ralli, Natascia and Isabella Stanizzi. 2009. "L'importanza delle note in terminografia: motivazione, tipologia, applicazioni”. In Mediazioni: Rivista online di studi interdisciplinari su lingue e culture.

(http://www.mediazioni.sitlec.unibo.it/no7-anno2009/61-articoli-no-7-2009/33limportanza-delle-note-in-terminografia-motivazione-tipologia-applicazioni.html)

de Groot, Gerard-René. "Das Übersetzen juristischer Texte". 1999. In Recht und Übersetzen, edited by de Groot, Gerard-René and Reiner Schulze: 11-46.

Eichinger, Ludwig M., Albrecht Plewnia \& Claudia Maria Riehl, eds. 2008. Handbuch der deutschen Sprachminderheiten in Mittel- und Osteuropa. Tübingen: Narr.

Fioritto, Alfredo. "Il linguaggio delle amministrazioni pubbliche". 2007. In Scrittura e società, Storia, Cultura e Professioni, edited by G. Fiorentino: 403-422.

ISO/TC37/SC1 N165 E. Terminology work - principles and Methods. Draft International Standard ISO DIS 704, 1999.

Istituto culturale mòcheno-cimbro http://www.jus.unitn.it/icmc/concdiramm.html (08.07.2010)

Muzii, Luigi. "La formazione in terminologia. Nuove esigenze formative: dal fare all'usare". 2006. In Mediazioni: Rivista online di studi interdisciplinari su lingue e culture. (http://www.mediazionionline.it/monografici/pulitano_ita.htm)

Pizzorusso, Alessandro. Corso di diritto comparato. 1983. Milano: Giuffrè Editore.

Prezzi, Christian. 2004. Isole di cultura. Saggi sulle minoranze storiche germaniche in Italia. Luserna: Centro Documentazione Luserna.

Pulitano, Donatella. 2006. "Il terminologo: cosa fa, cosa deve sapere, come si diventa". In Mediazioni: Rivista online di studi interdisciplinari su lingue e culture.

Ralli, Natascia. 2006. "Terminologia comparata dei sistemi giuridici: problematiche principali”. In Atti del $5^{\circ}$ Congresso dell'Associazione Italiana di Linguistica Applicata, Problemi e fenomeni di mediazione linguistica e culturale. Bari, 17-18 Febbraio 2005, edited by Banfi, E., Gavioli, L., Guardiano, C. and M. Vedovelli, 113-128. Perugina: Guerra Edizioni.

Ralli, Natascia. 2010. "Terminografia e comparazione giuridica: metodo, applicazioni e problematiche chiave". In Special Issue: Specialised Translation, InTRAlinea, online Translation Journal of SITLeC - University of Bologna. (http://www.intralinea.it/specials/specialised/ita_more.php?id=825_0_45_0_M)

RaDT - Rat für Deutschsprachige Terminologie. Professional Profile for Terminologists, 2004.

(http://www.iim.fh-koeln.de/radt/Dokumente/RaDT Berufsprofil englisch.pdf)

Rowley, Anthony. 2003. Liacht as de sproch. Grammatica delle lingua mòchena Grammatik des Deutsch-Fersentalerischen. Palù del Fèrsina: Istituto di cultura mòcheno-cimbro/Regione autonoma Trentino-Alto Adige.

Sager, Juan C. 1990. A Practical Course in Terminology Processing. Amsterdam/Philadelphia: John Benjamins B.V. 